\title{
VERTEBRAL VARIATION IN TELEOSTEAN FISHES. III. ISOSPONDYLI
}

\author{
By E. Ford, A.R.C.S., D.I.C. \\ Assistant Director of the Plymouth Laboratory
}

\section{INTRODUCTION}

In coming now, after a number of years of delay due largely to the war, to discuss vertebral variation in fishes of a particular order, the Isospondyli, it must be assumed that Parts I and II have been read (Ford, I937, I94I). In Part I a broad survey was made of the wide field of research presented by vertebral variation in teleostean fishes in general; Part II dealt expressly with vertebral statistics in the herring (Clupea harengus). In the present paper, observations mainly relate to the eight isospondylid species available for study at Plymouth, viz.:

\begin{tabular}{cll} 
Family & Genus & \multicolumn{1}{c}{ Species } \\
Clupeidae & Clupea & harengus, sprattus \\
& Alosa & alosa \\
& Sardina & pilchardus \\
& Engraulis & encrasicholus \\
Salmonidae & Salmo & salar, trutta \\
Argentinidae & Argentina & silus
\end{tabular}

By way of introduction it may be said that recognition 'on sight' is as real a thing with fish backbones as it is with whole animals, or with things and persons in everyday life. Some one feature is recognized or a mental picture catches the eye, which in our past experience we have learned to associate with a particular individual or class of individuals. Mayr (1942) very rightly points out that such discriminating characters may be, and very often are, of no particular importance to the species. But in so far as they serve as 'markers' they are of both interest and significance. The degree of their significance depends, of course, on what we wish to know, since the value of a vertebral character varies considerably as a diagnostic criterion.

In an isospondylid fish the variable characters of the backbone are numerous and the incidence of variation is often high. Consequently it is in practice little more than a matter of statistical routine to resolve a very large sample of backbones of the same species into individual specimens, each visibly different from all the rest. Yet, as has been suggested above, each specimen thus segregated nevertheless bears the unmistakable 'markers' of a particular species, both in the backbone as a composite whole and in every one of its components. I would even go as far as to suggest that 'markers' (or 'hallmarks', as I called them in Part II) of different biological groups of the same species are within practical possibility. On the other hand, it is equally 
straightforward to show that many of the vertebral characters are common to a number of species; and some of them are also to be seen in species at present outside the Isospondyli altogether.

This leads naturally to an enquiry into the composition and validity of the order Isospondyli itself. All that need be said here is that it must still be regarded as a somewhat tentative, if not entirely, artificial assemblage of diverse families, as distinct from a proven phylogenetic series (cf. Goodrich, I909, p. 386). Fishes which differ greatly in form and habit are brought together within its compass because they are believed to be among the most primitive of the teleosts; but comparatively little is known of the phylogenetic relationship between them or their ancestors (cf. Gregory, I933, p. I36). In such circumstances, it is not surprising to find much variation among the species within the order, as well as considerable agreement with others not included in it.

Lastly, some words of Gregory (I933, p. I49) are not without interest in the present work:

Thus the skulls of the Clupeidae afford numerous examples of what might be called a general principle of the morphology of the vertebral skeleton, namely that 'the holes are more important than the bones'; that is, the form and position of the bony tracts are largely determined by the form and position of the sensory vesicles, blood vessels, nerves, muscles, etc.; the strengthening ridges and eminences appear between and around the openings caused by the presence of the various parts mentioned above.

A similar statement might well be made concerning the vertebrae and their appendages which, according to the precise position they occupy along the length of the backbone, conform to the general lay-out of the body as a whole. Vertebral variation, therefore, may be studied as a reflection of variation in other bodily organs and parts.

\section{Primitive Vertebral Features in the Isospondyli}

Two vertebral characters are of wide occurrence among fishes of the order Isospondyli, namely, autogenous neural or haemal (or both) arches on a number of the vertebrae, and the bifid condition of some of the anterior neural spines. Garstang (I93I, p. 243) distinguishes between the 'archispondylous' condition of vertebral arches and the 'neospondylous' in which arches and centra are co-ossified, and we may agree with him in regarding the former as the more primitive. The archispondylous condition is very generally accompanied by bifid neural spines; that is to say, the spines arising from the left and right neural arches retain their separate identity above the neural canal, instead of becoming fused to form a single one.

These two characters are to be seen in fishes referred to orders other than the Isospondyli. For example, in the pike (Esox lucius), of the order Haplomi, the first 40 or so of the total of about 60 vertebrae (both numbers being subject to individual variation) have autogenous neural arches and bifid neural spines; in the pre-caudal vertebrae the haemal arches are also autogenous; while at the 
hinder end of the backbone, where vertebrae enter into the composition of the tail-root, both epural and hypural elements are likewise autogenous. In the order Apodes, the conger (Conger conger) has autogenous neural arches on the first I6 or I7 vertebrae, while in the freshwater eel (Anguilla anguilla) they occur on the first 5 vertebrae. In species of the order Ostariophýsi autogenous haemal arches are of very general if not universal occurrence.

Within the order Isospondyli itself, there is variation between two extremes. There are thus many species in which archispondylous vertebrae and bifid neural spines are comparatively numerous, but there are others in which all the vertebrae are neospondylous and all the neural spines single; the remaining species exhibit intermediate conditions between these two extremes.

During several short visits to the British Museum (Natural History) at South Kensington, I have by the courtesy of the Trustees and of the Director made a rapid survey of isospondylid skeletons with respect to these characters. The observations made, though very incomplete and subject to minor correction in light of more detailed study, may be briefly summarized as follows:

\section{CLUPEOIDEA}

ElopIDAE: In Elops machnata and Megalops cyprinoides the cylindrical vertebrae throughout the length of the backbone have autogenous haemal and neural arches. In Elops, vertebrae I-32, and in Megalops, vertebrae I-36, also have bifid neural spines.

Albulidae: In Albula vulpes, as in Elops and Megalops, all the vertebrae have autogenous haemal and neural arches; the neural spines of vertebrae I-30 are bifid.

Alepocephalidae: In $A$. rostratus autogenous neural arches are present only on vertebrae $\mathrm{I}-30$, the remainder being co-ossified with the centra; autogenous haemal arches occur only on vertebrae I-25, except for hypural elements in the tail-root; bifid neural spines are present on vertebrae I-3I.

Clupeidae: Species of the genera Clupea, Alosa, Sardina, Sardinella, Opisthonema, Harengula, Brevoortia and Nematalosa agree in having a specific number of autogenous haemal and neural arches, as well as of bifid neural spines. A common feature, perhaps a significant one, is that the number of vertebrae with autogenous haemal arches is less than that of vertebrae with autogenous arches which, in turn, is less than the number of vertebrae with bifid neural spines. In Clupea, Alosa and Sardina, of which many backbones are available for statistical study, it has been shown that there is marked specificity in these characters.

Engraulis encrasicholus agrees with the above species in having autogenous neural arches and bifid neural spines, but unlike them, the abdominal vertebrae show haemal arches co-ossified with the centra.

CHANIDAE: Chanos chanos has autogenous haemals on the first I2 or I3 vertebrae, and autogenous neurals on the first I6; but only the Ist (possibly also the 2nd) has bifid neural spines.

SALMONOIDEA: The condition in the salmonoid fishes is similar to that in many clupeoids. Autogenous haemal and neural arches, as well as bifid neural spines are thus to be seen in Salmo, Coregonus, Thymallus, Mallotus, Microstoma and Argentina. In Salmo salar and $S$. trutta, the number of vertebrae with autogenous neural arches is not substantially different from that of the vertebrae with auto- 
genous neurals; but in Argentina silus the number with autogenous haemals is much in excess. Autogenous epurals and hypurals are a feature of the primitive salmonid tail-root.

OSTEOGLOSSOIDEA: In Osteoglossum bicirrosum all the haemal arches seem to be co-ossified with the centra; and except for the first two neural arches, which may be autogenous, co-ossification appears to be the rule for the neural arches as well. Bifid neural spines occur only on the Ist vertebra.

NOTOPTEROIDEA: In Hyodon alosoides, although all the haemal arches seem to be co-ossified with the centra, the neural arches of vertebrae I to about 28 are autogenous; the neural spines of vertebrae $1-26$ are also bifid. By contrast, in Notopterus afer all haemal and all neural arches are co-ossified with the centra and all neural spines are single.

MORMYROIDEA: In Gymnarchus nilotus some 76 of the anterior neural arches and about 70 of the haemal arches appear to be autogenous; of the neural spines, the first 7 may be bifid. In Mormyrops anguilloides, Gnathonemius cyprinoides and Mormyrus kannume, the ribs are sessile on the abdominal vertebrae, but the neural arches are all co-ossified with the centra and the neural spines are single.

STOMATIOIDEA and GONORHYNCHOIDEA: No observations made.

Used as numerical variates the number of autogenous arches and bifid neural spines have an undoubted value in diagnosing species. To what degree they are also indicative of phylogenetic relationship between species, and hence may be used in the classification of fishes, is another question. While they are ancestral characters, they are not diagnostic of the orders, families and genera as at present constituted; but to reclassify the species in accordance with the condition of the arches and spines would produce merely another arbitrary series for which proof of natural affinity might still be lacking. Even so, they are characters which can be determined with precision and are constant enough to merit full consideration with other characters of like constancy in the work of classification.

It should be noted that, when making counts of vertebrae with autogenous arches, it is necessary to distinguish between counts along the left side of the backbone and those along the right, because these may differ (Ford, I937, p. I7; Ford, I94I, p. I58). Homoeotic variation of this kind is pronounced, both with the neural and the haemal arches. Thus in Clupea harengus, C. sprattus, Sardina pilchardus, Alosa alosa, Engraulis encrasicholus and Argentina silus, for which sufficient data for statistical study have been available, it can be taken as a general guide that in every roo backbones, not more than 60 and not less than 50 will give the same count of autogenous haemal arches on left and right sides; the corresponding estimates for autogenous neural arches are 70 and 60 . The matter has been pursued by drawing up correlation tables between left and right counts. It will suffice here to reproduce such a table (p. 394) giving the figures for this correlation in respect of autogenous haemal arches in a sample of roo pilchards (Sardina pilchardus).

It is seen that the arithmetic mean for the left-side counts differs little from that for the right, despite the fact that the counts along the two sides differ in 


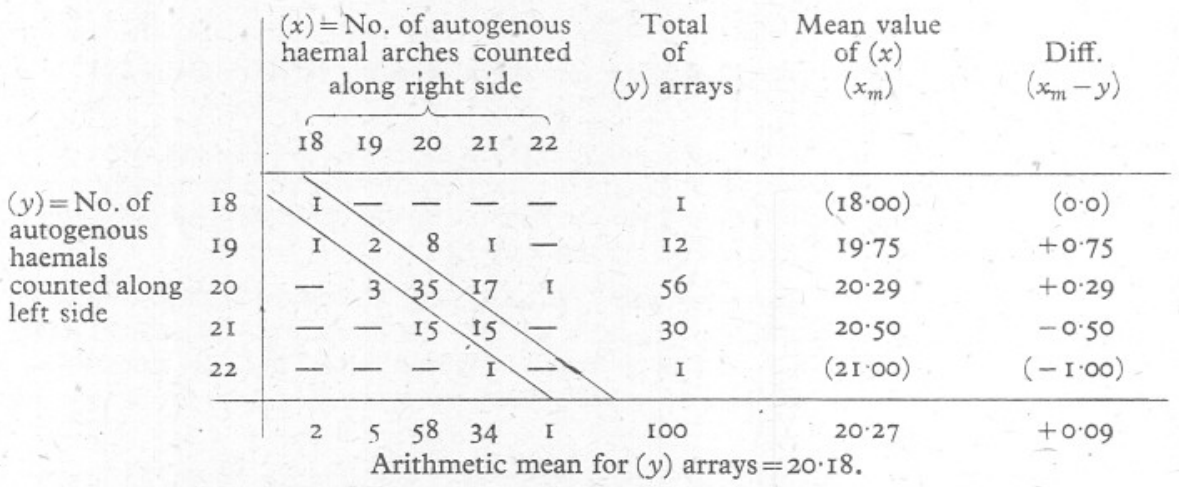

47 backbones. In only two specimens is the difference greater than $\mathrm{I}$, the rightside count in both cases exceeding the left by 2 . In the remaining 45 , where the difference is $\mathrm{I}$, the left-side count is the greater in 20 and the lesser in 25 . A comparison between the values of $\left(x_{m}-y\right)$ given in the right-hand column of the table shows, however, that the average right-side count is in excess when the value of $(y)$ is low, but falls short when $(y)$ is high. This is a curious result. I do not think it can be regarded as entirely fortuitous, for it is typical, not only for the pilchard, but for the herring and sprat. It has also been obtained in counts of autogenous neural arches as well. Maybe more study should be made of the significance of side-to-side variation in the teleostean backbone, particularly in isospondylids where it is so evident.

\section{Diagnostic Value of Vertebral Counts}

In Part II a statistical study was made of twelve counts which can be made along the length of a herring backbone. Each of these can be precisely defined and then determined by straight counting. With odd exceptions according to the species examined, these same counts can be made along the backbones of a great many other isospondylid fishes. Probably not one of them is, by itself, diagnostic of a particular species; but taken in conjunction, they not only diagnose the species but a single individual of that species. These counts are:

I. Pre-caudal vertebrae with autogenous haemal arch, as counted along left side of backbone.

2. As in (I) but counted along right side.

3. Pre-caudal vertebrae with 'open' haemal arch.

4. Vertebrae with autogenous neural arch, as counted along left side of backbone.

5. As in (4) but counted along right side.

6. Vertebrae with bifid neural spines.

7. Position in the vertebral series of a caudal vertebra with a characteristically enlarged haemal canal.

8. The number of vertebrae in the 'trunk' as counted along the left side.

9. As in (8) but counted along right side.

I0. The number of vertebrae in the 'tail-root' (i.e. vertebrae in which the haemal spines are cross-tied to the centra), as counted along the left side.

II. As in (IO) but counted along right side.

I2. Total count of vertebrae between the skull and the terminal urostylar segment. 
There is little point, I feel, in going into detail concerning the absolute values and degree of variation for each of these counts in the particular eight species examined at Plymouth. The points to be emphasized are (a) that they are precise measurements of variation, and $(b)$ they could be used in statistical analyses intended to distinguish between species and species, or between biological groups of the same species, over a wide range of fishes. The conclusions which can rightly be drawn from their use in this way must clearly depend upon the particular circumstances of the enquiry. In other words, the counts are instruments-effective instruments if correctly used-to be employed in diagnosis.

But, as was said in the introduction, there is another kind of vertebral character which is more direct in its diagnostic indication than any of the counts described above. Such characters or 'markers' may be more difficult to define, because their diagnostic value rests less upon their absolute value as a statistic than upon the actual visual impression they create in the observer's eye. The form-picture presented by a piscine backbone is really a composite one, spread over a graded series of separate elements, the vertebrae, each of which normally differs only a little from its neighbours. Every species presents a different picture depicting the sum-total of variation from one vertebra to the next throughout the backbone. It is not to be expected that such a picture can be easily defined, but it is none the less real, both as a whole or in its separate parts.

In the eight isospondylid species available for study at Plymouth, three families and six genera are represented. The briefest inspection of the tail-root suffices to distinguish between the clupeoids and the salmonoids. Of the latter the two species of Salmo are readily separable from Argentina by the characteristic sculpturing of the centra and the form of the neural and haemal arches. Of the clupeoids, Engraulis can at once be placed apart from the rest because of the long series of unbridged haemal processes co-ossified with the centra of the pre-caudal vertebrae. There remain two species of Clupea, one of Sardina and one of Alosa. Sardina pilchardus and Alosa alosa agree in showing a strong development and elaboration of both neural and haemal apophyses, with a very pronounced interlocking of vertebrae in the tail-base, and are readily distinguished from Clupea harengus and C. sprattus. The backbone of Alosa alosa will not be mistaken for that of Sardina pilchardus because it reflects in its over-all form the much greater depth of body in Alosa, and is more clear-cut in its vertebral elaboration. It is less easy to describe the difference between the backbone of a sprat and that of a herring comparable in size, since both are more generalized in form. Possibly in this particular instance it would be safer to fall back on one or two of the statistical counts, which would certainly establish identity. This, however, is not necessary for an observer who has had occasion to handle herring and sprat backbones frequently.

These observations, of course, relate to a very small number of well-known JOURN. MAR. BIOL. ASSOC. vol, XXVI, I 946 
species, but they are quite sufficient to illustrate the nature and usefulness of vertebral 'markers': by their use, species have been both identified and classified. Their limitations have been exemplified in a comparison between the herring and sprat, where more precise diagnostic criteria might with advantage be employed.

\section{The BaCKBone as a Bodily Component}

Generally speaking, the morphological 'lay-out' of any fish is largely reflected in the form of the backbone. This is rather to be expected in a metamerically segmented animal, organized about a long axis, the backbone itself. Seeing that the number of segments is large, while basic metamerism is in great measure persistent, counts of successive vertebrae are often counts of other repetitive organs also. In Part II (Ford, I94I, p. I67) it was shown that in the herring there exists this kind of correlation between vertebral counts and the number of 'keeled scales' situated along the mid-ventral line of the body between the head and the anus. This is true also for the pilchard, sprat and shad, each species, however, presenting some variation in the immediate region of the pelvic fin.

Another correlation of this kind exists between the anterior neural spines and a median series of bony elements between the head and the insertion of the dorsal fin. ${ }^{1}$ The first of the series lies immediately anterior to the neural spines of the first vertebra, and the succeeding ones in front of the neural spines of the second, third, etc., vertebrae, to the end of the series. The last one is thus immediately anterior to the first radial element of the dorsal fin (vide Ford, 194I, fig. 3). In the herring the total number in the series is about I7 or 18; it is of a similar order in the sprat, but is much reduced to the order of Io or II in the pilchard. From casual observations made at the British Museum it is believed that this count would prove of great taxonomic use over a wide range of species.

The study of alizarin-stained dissections and radiographs makes it possible to express other bodily features, both external and internal, in vertebral terms. For example, the siting of the fins and anus, the boundaries and contour of the body cavity, can be correlated with the vertebrae by tracing the path of the ribs, false ribs, and other vertebral processes, from the feature in question back to the vertebrae themselves. The accumulated knowledge thus obtained affords the means of interpreting differences to be observed in the isolated backbone, and of actually visualizing in the latter the form of the whole fish. It does not take long in such studies to realize that pronounced differences in external bodily form are often concomitant with comparatively small differences in the form of associated vertebral structures. In point of fact, both

1 There still appears to be some difference of opinion as to the homology of these bony elements (vide Eaton, 1945). Whether they are to be considered as distal, separately ossified, elements of the neural processes, or as vestigial elements of a pre-existent median fin, need not concern us here. 
are concomitants of differences in the configuration of the complexly folded and $\mathrm{W}$-shaped myomeres, which are fundamental in nature. It is easily appreciated that a comparatively small difference in the relative lengths of the arms of the W, and of the angles subtended by the arms, must result in change of position of all structures associated with the myomeres; and the farther removed from the centre of the myomere a structure is, the more pronounced will be the change in its position. The only alternative to this is the actual breaking down of the meristic agreement-which does occur during ontogeny, when the fins move in relation to myomeres and vertebrae, in the act of metamorphosis from the post-larval to adolescent stage.

\section{SUMMARY}

This paper does not give a detailed description of the backbone of any one of the eight isospondylid species examined. Instead, selected data have been used in a discussion of the broad principles of vertebral variation, as seen in fishes of the order Isospondyli. This was considered to be of greater value than a catalogue of vertebral details for each of a small number of already wellknown species. Even so, sufficient has been said to enable any worker to identify the backbone of any one of the eight species, as well as to obtain a most discriminative description of the backbone of any other species of Isospondyli he may examine. A distinction is drawn between the countable vertebral characters, which are statistics for the precise measurement of vertebral variation, and the 'marker' characters, which provide the means for recognition 'on sight'. It is believed that vertebral characters of both kinds might be profitably employed in the study of different biological populations of the same species. The correlation between vertebral characters and other bodily features, such as keeled scales, position of fins and anus, and contour of body cavity, receives attention, and is related to metamerism. Finally, the occurrence of autogenus vertebral arches and the bifid condition of the neural spines in the isospondylid backbone is shown to be primitive and not restricted to the order.

\section{REFERENCES}

EAton, T. H. Jr., I945. Skeletal supports of the median fins of fishes. Fourn. Morphology, Vol. Lxxvi, No. 3, p. I93.

Ford, E., 1937. Vertebral variation in teleostean fishes. Fourn. Mar. Biol. Assoc., Vol. xxIr, pp. I-60.

- I94I. Vertebral variation in teleostean fishes. II. The herring (Clupea harengus L.). Fourn. Mar. Biol. Assoc., Vol. xxv, pp. I5I-72.

Garstang, W., I93I. The phyletic classification of teleostei. Proc. Leeds Phil. Soc. (Scient. Sect.), Vol. II, Part v, pp. 240-60.

Goodrich, E. S., 1909. A Treatise on Zoology, Part Ix, Vertebrata Craniata. London.

GREGORY, W. K., I933. Fish skulls: a study of the evolution of natural mechanisms. Amer. Phil. Soc., Philadelphia, Art. II, Vol. xxirI.

Mayr, E., I942. Systematics and the Origin of Species. No. xirr, Columbia Biol. Ser., New York. 